\title{
From a distance and generalizable to up close and grounded: Reclaiming a place for qualitative methods in international business research
}

Julian Birkinshaw, Mary Yoko Brannen and Rosalie L Tung

Special Issue Guest Editors

Journal of International Business Studies (2011) 42, 573-581. doi: 10.1057/jibs.201।.19
It is exhilarating to write the introduction to this Special Issue as it presents an important opportunity for qualitative research to reclaim its position as an integral part of international business (IB) research. The field of IB was founded on a rich qualitative research legacy (e.g., Bartlett, 1979; Crozier, 1965; Fayerweather, 1969; Johanson \& Vahlne, 1977; Kindleberger, 1956; Prahalad, 1975; Wilkins, 1970, 1974). Over time, however, such methods have been progressively marginalized in our field as quantitative methods have become the norm. This shift in emphasis has mirrored the broader trend toward more positivistic empirical methods in the social sciences. The field of IB is "multidisciplinary in scope, and interdisciplinary in content and methodology" (statement of JIBS editorial policy). However, as our respective home disciplines came under growing pressure to solidify their legitimacy as scientific endeavors that merit scholarly attention, it is not surprising that we began to take on the norms propagated within our own academic communities that typically equated quantitative data with "hard science".

While there are clear merits associated with quantitative methods, the multi-cultural, multi-dimensional and dynamic nature of the field of IB lends itself to a broad range of research methodologies, qualitative methods being one of them. In order to understand the complexities of emergent and evolving phenomena scattered over distance, and the differentiated contexts typical to many topics under investigation in IB, it is often inappropriate to engage in large-scale, cross-sectional studies or reductionist methods in the absence of well-developed theory. Rather, thick description, exploratory research and comparative case analysis that focus on inductive theory building and hypotheses generation may be more suitable.

There is a growing recognition of the value of qualitative research in IB, with some important attempts to bring it closer to the fore (e.g., Marschan-Piekkari and Welch's 2004 Handbook of Qualitative Research Methods for International Business). However, despite the efforts of some scholars and journal editors, the number of articles in leading journals in IB that use qualitative methods remains relatively low (see the Welch et al. paper in this Special Issue). This is a particular loss in our field, where qualitative methods can 
once again play a critical role to interpret and understand the complex plurality of contexts institutional, cultural, organizational and so on, brought about by globalization - and the linkages between them and firms that transact business across international boundaries. With the maturing of the field of international business comes a need for a more nuanced understanding of its fundamental constructs.

Take, for example, one of our most ubiquitous constructs in international business: culture. The most widely used measures of cultural differences in our research - Hofstede, GLOBE and Schwartz are all value-based. Because values are only one manifestation and not the sum total of a country's culture, they cannot fully capture the value-behavior link. This deficiency explains, in part at least, why there are often conflicting findings with regard to the impact of select cultural dimensions on managerial behavior and firm strategy. The quantification of cultural differences have taken us perhaps as far as we can go, beyond which the law of diminishing returns will most likely set in. Qualitative methods, on the other hand, can take us beyond Hofstede (1980) and GLOBE (Tung \& Verbeke, 2010) to generate new conceptualizations and interpretations of culture that will enable us to make sense of increasingly complex cultural phenomena. These include such current topics as biculturalism, multicultural work teams and the role of cultural hybrids that are emerging rapidly in light of new workforce demographics; global strategies of emerging market multinationals as the center of gravity of internationalization shifts from West-East to South-North and as the epicenter of economic growth comes from outside of North America-Western Europe; and so on. An accurate understanding and interpretation of these phenomena can be of enormous benefit to multinational corporations (MNCs).

Taking the widely known case of Carlos Ghosn, Chairman and CEO of Nissan Motors, as an example, quantitative-based cultural dimensions are of limited value in understanding his success in revitalizing the aging Japanese automobile manufacturer. For one thing, indicative of the challenge in cultural typing of today's complex cultural individuals (see Brannen \& Thomas, 2010), it is not clear which country's scores should be used to characterize Ghosn. He was born in Brazil, he is a French citizen, the offspring of a Lebanese father and a French mother, and he speaks six languages including Arabic and now some Japanese. Qualitative research methods are likely to better capture the complex nature of his rich life experiences and yield a more nuanced understanding of how Ghosn was able to intuitively combine his accomplished change leadership skills with deep cultural insight in a national cultural context of which he had relatively little knowledge.

Qualitative methods are characterized by a firsthandedness in which researchers strive to be at one with their research phenomena in a way that other methods do not require, sanction or even encourage. This is particularly significant in our field where many of our researchers have deep contextual knowledge of diverse cultural contexts by virtue of their country-of-origin, upbringing or education and thus are inherently gifted with budding participant observer skills. It is tragic not to leverage such basic research skills and competencies toward strong and novel contributions to IB research. With this Special Issue, we would like to reclaim a place for qualitative methods and bring them back into the mainstream of IB research. In this Special Issue, we adopt Van Maanen's (1979: 520) definition of qualitative research as "an umbrella term" to cover an "array of interpretive techniques that can describe, decode, translate, and otherwise come to terms with the meaning, not the frequency, of certain more or less naturally occurring phenomena in the social world".

\section{THE EVOLUTION OF IB RESEARCH: NEW OPPORTUNITIES FOR QUALITATIVE RESEARCH}

Many different research traditions have come together to create the field of international business as we know it today, including business history, economics-based studies of foreign direct investment, organizational sociology, industrial-organizational psychology, anthropology, cross-cultural communication and process-based perspectives of the nature of the MNC. Based on a content analysis of 526 publications, Roberts (1970: 327) characterized these efforts as similar to various individual perspectives on "looking at an elephant"; that is, depending upon the researcher's home discipline and hence vantage point, the beast (international business in this case) can appear vastly different. Because of its eclectic roots, IB research has gravitated over the years toward the use of discipline-based theories and quantitative, positivist methodologies, with a corresponding decline in cross-disciplinary perspectives and qualitative 
methodologies. This more focused perspective has brought certain advantages, including a greater level of recognition among scholars based in cognate areas such as strategic management and organizational behavior. However, this growing convergence in perspective has also resulted in missed opportunities in a number of areas:

- Studies of the internal organization of MNCs have become relatively rare. The landmark studies of the 1980s sought to examine the internal dynamics of large MNCs, focusing on such things as decision-making processes and the interaction between the formal and informal organization (Bartlett \& Ghoshal, 1989; Hedlund, 1986; Prahalad \& Doz, 1987). Over the last 20 years, however, this approach has been largely superseded by network conceptualizations of the MNC and a focus on such concepts as subsidiary autonomy, influence and centrality (e.g., Andersson, Forsgren, \& Holm, 2007; Ghoshal \& Bartlett, 1990). Such approaches are attractive in no small measure because they are amenable to measurement and testing using quantitative techniques. And while they have led to useful insights, they have done so by downplaying many of the informal processes that enable large MNCs to deliver on their objectives.

- Research on knowledge in MNCs has typically failed to distinguish between simple (codified, explicit, binary, universal, unambiguous) knowledge that can be researched using traditional quantitative methods and complex knowledge (tacit, implicit, systemic, endemic, context dependent) that requires more "up-close and grounded" qualitative types of methodologies. This distinction is important because simple knowledge is much less likely to require deep contextual understanding to be meaningful and is less vulnerable to recontextualization when transferred to and applied in a new context (Brannen, 1992, 2004). As a result, many of the real challenges of knowledge exchange and technology transfer have been misrepresented or overlooked.

- There is an understandable tendency toward conceptual abstraction in many areas of IB research, for example in process studies of the MNC (e.g., Ghoshal \& Bartlett, 1994; Hamel \& Prahalad, 1983; Malnight, 1996) and in crosscultural research (e.g., Boyacigiller \& Adler, 1991). However, conceptual abstraction can also create problems of interpretation and application. For example, in cross-cultural research many IB researchers have become partial and rudimentary translators of contextual differences - reducing them to a few practices such as gaunxi in China or kaizen in Japan. As a result, when individuals with varying pre-conceptions about each other's multiple cultures and contexts attempt to transfer, synchronize, learn from and even co-create, the use-value of these aggregate level constructs begins to seriously break down (Brannen, 2004; Brannen \& Salk, 2000; Tung \& Verbeke, 2010).

While not in any way exhaustive, the list above highlights some of the major research opportunities in the IB field. And taken as a whole, one can observe that somewhere between the bird's-eye view of economists and strategists, in their attempt to develop theories that apply to all organizations and societies, and the more grounded perspective of many individual-level studies lies a critical void, or, perhaps more aptly put, a missing link.

We believe that qualitative methods can play an important role in overcoming this missing link through the provision of a deeper understanding of micro-processes and of the interplay between culture and context in the collaboration and integration of activities. This in turn would provide us with an intermediate level of analysis to help us understand individuals collaborating across contexts that so far has largely eluded organizational process scholars. As noted by Cheng, Henisz, Roth, and Swaminathan (2009: 1072): "moving forward is not about reformulating novel dependent or independent variables; it is about addressing a phenomenon that can only be unpacked by combining theories, concepts, data and methods from multiple disciplines to explore the scope of boundary conditions of multiple disciplinary perspectives and the benefits of their integration". Qualitative research is particularly suited to "unpacking" phenomena of interest because it encompasses a diverse set of "interpretive techniques" that can provide a deeper and richer understanding of the issues under investigation (Van Maanen, 1979: 520).

Rather than merely comply with discipline-based methodological approaches that render us subordinate to other scholarly fields of inquiry, we believe that IB researchers need to leverage and exploit our unique capabilities and perspectives. This is particularly important in light of the growing interconnectedness of societies around the world and the rising influence of norms and traditions outside of the North America-West Europe orientation that 
has characterized knowledge generation in the past century and a half. We should capitalize on the diverse multicultural backgrounds of our researchers and the unique perspectives that they can bring to the IB field, so that we can become "sources of ideas" and not merely "storers" (Sullivan, Nerur, \& Balijepally, 2011).

One way by which we can accomplish this is to deviate from the norm that has been popular in our field in the past two decades and to put a greater emphasis on qualitative research (Cavusgil, Griffith, \& Xu, 2008). We are not suggesting an abandonment of the quantitative methods that have served the field well; rather, we are advocating a judicious mixture of qualitative and quantitative approaches, a combination that Jick (1979: 602) characterized as "triangulation in action".

The multi-faceted, contextually situated interactions that characterize today's complex cultural organizations demand a more nuanced epistemological approach rather than a predominantly positivist one (Redding, 1994). A constructive interplay between paradigms and the application of multiple research methods would help open the way toward mid-range, process-based theories that might then lead to more dynamic as well as robust models for understanding the interaction between global leaders, foreign managers and host country employees in the unfolding of MNCs and in their collaboration across borders. As Tung (2008) observed, in light of brain circulation and the growing movement of talent across international boundaries, even the standard notions of who are "foreign managers" and "host country employees" are subject to reinterpretation. Thus, instead of a grand theory of acculturation for expatriates that seeks to capture the modes by which members of a minority culture interact with those from the majority culture, a mid-range theory that finetunes the categories of members of majority and minority cultures can shed greater insights into that process. Mid-range theories focus on a "unique set of images" (Pinder \& Moore, 1979: 100) that characterize observable aspects of separate social phenomena, rather than the more ambitious attempt to build "grand theories" (Merton, 1968) that seek to explain activities and actions across all societies (Ritzer, 1975).

\section{OVERVIEW OF THE SPECIAL ISSUE}

Our call for papers generated 118 submissions - a record number of submissions to a special issue of $J I B S^{1}$ and an indication that providing a forum for qualitative IB research appears to be long overdue. Out of this set of submissions, we accepted nine for publication in the Special Issue. ${ }^{2}$ Due to page limit constraints seven out of these accepted papers are included herein and two will be published in the issue directly forthcoming. In total, these nine papers exhibit a range of methodologies including ethnography, case study, discourse analysis, phenomenography and "fuzzy set" QCA, and they employ a variety of modes of theorizing from conceptual induction and interpretive analysis to cross-paradigmatic meta-analysis. Collectively, these papers are a terrific tribute to qualitative research they showcase what high-quality qualitative research looks like, and they provide us with a deeper understanding of when, how and why such methods might be particularly appropriate to IB research.

In addition to the double-blind peer review process, we solicited short perspectives papers from four eminent scholars (these were single-blind reviewed, in accordance with JIBS policies). As a means of furthering the dialogue between the disciplines and the field of international business, we joined two seasoned IB qualitative scholars Yves Doz representing the strategic management discipline and Eleanor Westney representing organizational studies - with two seasoned non-IB qualitative researchers - Robert Burgelman in strategic management and John Van Maanen in organization studies. We asked them to consider such questions as: What are the challenges in conducting qualitative research in a global context? What are your frustrations or concerns about the nature of qualitative research being conducted in the field of business/management today? And what do you see as the exemplars of qualitative research over the last 20 years?

In the first paper, "Qualitative research for international business", Yves Doz provides a very useful overview of the challenges and opportunities faced by our field. Doz argues that the multidisciplinary nature of IB makes qualitative research particularly valuable in that it allows us to build and test new theories, illustrate and exemplify new phenomena and surface contextual differences between countries. Like ourselves, though, he feels that the field has lost its way with its push toward quantification and its use of partial theories borrowed from other disciplines. He finishes his article with some specific suggestions for how higher-quality qualitative research can be done and the emerging opportunities it will enable us to address. 
In "Bridging history and reductionism: A key role for longitudinal qualitative research", Robert Burgelman first reviews the principles of grounded theory ${ }^{3}$ (Glaser \& Strauss, 1967) and the use of historical methods for studying how events play out over time (Gaddis, 2002). He then puts forward the intriguing idea that longitudinal qualitative research strengthened by modern historical methods can play a bridging role in theory development between narratives on the one hand and reductionist, abstract theories on the other. Such studies help us to understand key aspects of complex social processes captured in historical narratives, while also providing stepping stones toward the development of better grounded, statistical and mathematical models based on novel and imaginative conceptual frameworks. When done well, this approach can help to secure a distinctive place for qualitative research in IB.

"The casual ethnography of the executive suite" by Eleanor Westney and John Van Maanen offers a thoughtful challenge to those researchers who already see interviews with senior executives as an important part of their methodological toolkit. The landmark studies of Chris Bartlett, Sumantra Ghoshal, Yves Doz and others are characterized here as "casual" ethnography - full of insight into the real-life workings of MNCs through up-close observation, but ultimately offering a partial view because of the emphasis on the views of top-level executives. Westney and Van Maanen argue that the IB field could benefit, in addition, from more studies based on "serious" ethnography, which in an MNC means examining "the perspectives of the less powerful, and how they influence, interact with, interpret and respond to the wishes of the powerful".

We follow our invited papers with the nine submitted papers that went through the double-blind review process, leading with three ethnographies that venture deep beyond the executive suite. In "Foreign locals: A cautionary tale on the culture of MNC local employees", Dan Caprar utilizes a realist ethnographic approach (Cunliffe, 2010) to advance a nuanced understanding of the host country nationals (HCNs). Through a series of focus groups, semi-structured interviews (with not only the HCNs but also spouses of the HCNs) and ongoing participant observation in a Romanian subsidiary of a large MNC, he discovers that there is a range of ways in which HCNs experience and evolve in their de facto bicultural roles, in which they must navigate their organizational identity between their Romanian host context and the organizational culture of the North American MNC. His study is an example of how thoughtful ethnographic inquiry can lead to new insights around the effects (both good and bad) of complex cultural contexts on individuals in MNCs that can then inform progressive practices in managing more effectively and compassionately across cultures.

In "Boundary work: An interpretive ethnographic perspective on negotiating and leveraging crosscultural identity", Noriko Yagi and Jill Kleinberg show how such an in-depth ethnographic approach can yield new insights into the role of boundaryspanners in the ever-increasing number of bicultural organizations resulting from internationalization and the global integration of MNCs. In addition to providing a conceptual framework for understanding the role of boundary-spanners, their piece goes far in elucidating the nature of boundary work, in particular revealing the often improvisational nature of such work and consequently the individual-level competencies and organizational support required to nurture and sustain it.

In "Holistic ethnography: Studying the impact of multiple national identities on post-acquisition organizations", Fiona Moore adopts a holistic ethnographic approach in her study of BMW MINI to gain insights into cross-cultural relationships in the post-M\&A operations between British Rover and German BMW in their Cowley Works' plant in Oxfordshire, UK. Moore worked for 3 months as a line employee in the Final Assembly Area of the Cowley Works plant to produce a rich picture of how the complex interactions of ethnicity, gender, crossnational culture (British vs German) and organizational culture (Rover vs BMW) can contribute to conflicts, how these conflicts were resolved, and how these cross-cultural relationships ultimately affected integration of the acquired subsidiary. As a participant-observer, Moore is able to build the necessary rapport with her subjects to allow them to talk freely about these issues of a sensitive nature.

In "Small firm internationalisation unveiled through phenomenography", Peter Lamb, Jörgen Sandberg and Peter Liesch introduce phenomenography as a compelling method for understanding variations in strategy implementation in international business. In this case, the authors describe and document four distinct ways in which small owner-managed wineries in Australia have organized and managed internationalization. By so doing, the authors inform IB researchers of a useful qualitative technique for unbundling variations in the rational behaviors of managers across different organizational, industry and country contexts. 
In "Predicting stakeholder orientation in the multinational enterprise: A mid-range theory", Donal Crilly asks, for whom is the corporation managed? This question is particularly salient at the foreign subsidiary level, where subsidiary managers are accountable to their parent company to deliver economic value, while also facing demands from a range of local stakeholders - the host government, the community and local employees. Crilly uses a clever mixed-method study, first conducting interviews in 53 subsidiaries of 13 MNCs and then employing fuzzy-set analysis to validate his emerging ideas. He finds that some subsidiaries do indeed emphasize local stakeholders alongside their corporate parent, while others are single-mindedly focused on the latter. He then shows that those with the "broad" objective function tend to be the ones with an R\&D establishment, with all its attendant linkages to the local economy, and also those with a local national running the operation when it is in a developing country.

In "Microlending in emerging economies: Building a new line of inquiry from the ground up", Garry Bruton, Susanna Khavul and Helmuth Chavez focus on the opportunities associated with that large segment of the world's population characterized by CK Prahalad as the "bottom of the pyramid". Through interview-based case studies of microfinancing practices in Guatemala and the Dominican Republic, Bruton et al. identify the factors that have contributed to the success and failure of microloans. Since women typically have less access to traditional loans, they represent natural subjects for such investigations. Given the emergent phenomenon of microlending, in-depth interviews with loan recipients have shed useful insights on these practices resulting in the generation of six testable propositions that could lay the foundation for subsequent theory development on microlending.

Catherine Welch, Rebecca Piekkari, Emmanuella Plakoyiannaki and Eriikka Paavilainen-Mäntymäki's piece, "Theorising from case studies: Towards a pluralist future for international business research", anchors this volume by making two very important contributions to this Special Issue. It provides a meta-analysis of qualitative research in IB research, documenting the paucity of such studies in our field. And, more importantly, it provides inspiration and direction for researchers to go beyond using the case study solely as a tool for inductive theory-building and to consider and take on its theorizing potential, both in terms of generating causal explanations and contextualizing theory.
Our final two papers, which will follow in the next issue of $J I B S$, employ distinct variations on qualitative methodologies for analyzing how individuals talk about their work lives in multinational organizations.

In "Selling, resistance and reconciliation: A critical discursive approach to subsidiary role evolution in MNEs", Julia Balogun, Paula Jarzabkowski and Eero Vaara employ a critical discursive approach to a study of the relationship between the HQ and subsidiary in one MNC. Most prior studies of HQsubsidiary relations have either focused on topdown control by the parent or bottom-up initiative from the subsidiary. Here, the authors examine how the two processes interacted during a major change initiative. They use discourse analysis (an established methodology in the social sciences that is not well known in IB) to analyze how people talked or wrote about the change process they were experiencing. They observe three distinct discourses over the period of study - selling by the parent, resistance from the subsidiary and reconciliation - and they describe how these discourses shaped the behaviors and attitudes of employees in the MNC.

Using narrative inquiry, Martine Gertsen and Anne-Marie Søderberg's paper, "Intercultural collaboration stories: On narrative inquiry and analysis as tools for research in international business", furthers our understanding of intercultural collaboration in MNCs. Analyzing stories told by two managers, a Dane and a Chinese working in a Chinese subsidiary of a Danish MNC, the authors introduce the capacity of narrative theory and narrative interviewing to elucidate the iterative dynamics of sensemaking in MNCs. By carefully studying one narrative dyad, the authors are able to track the interaction process and to show how the actors' mutual efforts to collaborate involve not only navigating their ways through different types of knowledge, values and behavior but also the evolution of their ongoing sensemaking around these differences. The study thus shows how a narrative approach offers possibilities to capture the richness of discursive interchanges that can then lead to new insights into traditional international business constructs such as intercultural collaboration.

\section{HOW SHOULD WE DO, WRITE UP AND CRITIQUE QUALITATIVE RESEARCH?}

While it would be inappropriate to draw any definitive conclusions from the assembled body of papers, our vantage point as editors of the Special Issue allows us to make a few general observations 
about what makes for a good and publishable qualitative study. These tips are neither comprehensive nor profound, but given the high variation in the quality of submissions we received, we believe they are important for any qualitative researchers to consider (see also Van Maanen (1979) in the Administrative Science Quarterly, as well as some recent editorials in the same vein, notably Pratt (2009) and Gephardt (2004) in the Academy of Management Journal; as well as Golden-Biddle \& Locke (2007)).

\section{Choose a Topic Carefully}

The first challenge with doing qualitative research is simply choosing what to study. Because qualitative work is often done in exploratory settings, that is, studying topics that are new to the field or hitherto under-researched, it is perhaps more important than ever to make sure that the subject matter under investigation is truly novel and meritorious of research attention. We might be seduced into thinking we are onto something really new and different while out in the field, but it is important to step back, ground what we are seeing in current research and ask ourselves if what we are seeing is truly novel as well as helpful for understanding newly emerging patterns and trends in the international business domain. According to the criteria articulated in the JIBS Statement of Editorial Policy, the research topics under consideration must involve "cutting-edge research that breaks new ground, rather than merely making an incremental contribution to international business studies ... and include a clear statement of what it is they contribute to international business research".

\section{Explain Why a Certain Methodology Was Chosen} In many of the manuscripts we reviewed, it was not clear whether the research question guided the choice of methodology, or vice versa. While we fully accept that every individual has personal preferences for the type of research they conduct, it is still necessary for authors to justify their choice of methodology, logically and clearly. In other words, the research question should guide the choice of methods, and the methods section should clearly articulate why the particular qualitative method or combination of methods is appropriate for the objectives of the study.

\section{Be Transparent and Detailed about the Research Method}

The most frequent problem we found with submissions to the Special Issue was the absence of a robust description of the methodology. This may be due to the lack of a commonly accepted template for writing up such research (Pratt, 2009); it may also be due to a lack of training, as few $\mathrm{PhD}$ programs provide courses in qualitative methods or sanction engaging in it (see Yves Doz's further discussion of this point in this Special Issue). Thus, while many PhD graduates may be very adept in using quantitative methods, they may be ill-equipped to conduct, write and review qualitative research. In many cases, the authors offered a perfunctory nod toward a particular methodology, for example, by citing Glaser and Strauss (1967) or Eisenhardt (1989), but without giving any explanation of how the data were obtained or analyzed. To be publishable, a paper needs to help the reader understand the process by which the data were collected and interpreted. Researchers must also articulate how they bound their study, for example by explaining how they chose their subjects, why they chose the particular interviews that are presented in their data, and so on.

\section{Remember that Exploratory Research Does Not Imply Absence of Theory}

Many studies that employ qualitative methods are exploratory in nature, meaning they seek to understand phenomena that are poorly understood. However, we observed a tendency among some authors to use their exploratory framing as a license for offering purely descriptive insights, or for what might be called casual theorizing, not linked to any existing bodies of work. Papers using such approaches did not receive good reviews. Our view is that qualitative research methods are particularly well suited to rigorous theory development, which means both framing the study in terms of existing debates in the literature, as well as being explicit about what body of theory(ies) it is building upon, and why.

It is our hope that these tips, accompanied by the insights and suggestions offered by our invited papers along with the nine peer-reviewed articles, will go a long way in providing guidance for future qualitative IB researchers and offering readers and reviewers of qualitative studies an understanding of what good qualitative research looks like, along with an appreciation of what it can do to advance theory building in IB. In this way, qualitative research can once again capitalize on its rich legacy that contributed so much to building the field of IB research in its early years and re-establish the pivotal role that it can play in the further development of the field. 


\section{ACKNOWLEDGEMENTS}

We thank Lorraine Eden for championing this Special Issue and the two anonymous reviewers for their valuable feedback and suggestions that have greatly improved our introduction.

\section{NOTES}

${ }^{1}$ The influx of submissions gave us the wonderful opportunity of working with a variety of authors and themes toward furthering qualitative IB research. Though only a small portion of the submissions made their way into this Special Issue, we are heartened by the enthusiasm and look forward to many more papers

\section{REFERENCES}

Andersson, U., Forsgren, M., \& Holm, U. 2007. Balancing subsidiary influence in the federative MNC: A business network view. Journal of International Business Studies, 38(5): 802-818.

Bartlett, C. A. 1979. Multinational structural evolution: The changing decision environment in international divisions, Unpublished doctoral dissertation, Harvard University, Cambridge, MA.

Bartlett, C. A., \& Ghoshal, S. 1989. Managing across borders: The transnational solution. Boston, MA: Harvard Business School Press.

Boyacigiller, N., \& Adler, N. J. 1991. The parochial dinosaur: Organizational science in a global context. Academy of Management Review, 16(2): 262-290.

Brannen, M. Y. 1992. Bwana Mickey: Constructing cultural consumption at Tokyo Disneyland. In J. Tobin (Ed.), Remade in Japan: Consumer tastes in a changing Japan: 216-264. New Haven, CT: Yale University Press.

Brannen, M. Y. 2004. When Mickey loses face: Recontextualization, semantic fit, and the semiotics of foreignness. Academy of Management Review, 29(4): 593-616.

Brannen, M. Y., \& Salk, J. E. 2000. Partnering across borders: Negotiating organizational culture in a German-Japanese joint venture. Human Relations, 53(4): 451-487.

Brannen, M. Y., \& Thomas, D. C. 2010. Bicultural individuals in organizations: Implications and opportunity. International Journal of Cross-Cultural Management, 10(1): 5-16.

Cavusgil, T., Griffith, D. A., \& Xu, A. 2008. Emerging themes in international business research. Journal of International Business Studies, 39(7): 1220-1235.

Cheng, J. L. C., Henisz, W. J., Roth, K., \& Swaminathan, A. 2009. Advancing interdisciplinary research in the field of international business: Prospects, issues and challenges. Journal of International Business Studies, 40(7): 1070-1074.

Crozier, M. 1965. The bureaucratic phenomenon. Chicago, IL: University of Chicago Press.

Cunliffe, A. L. 2010. Retelling Tales of the field: In search of organizational ethnography 20 years on. Organizational Research Methods, 13(2): 224-239.

Eisenhardt, K. 1989. Building theories from case study research. Academy of Management Review, 14(4): 532-550.

Fayerweather, J. 1969. International business strategy and administration. Cambridge, MA: Ballinger.

Gaddis, J. L. 2002. The landscape of history: How historians map the past. Oxford: Oxford University Press.

Gephardt, R. 2004. Qualitative research and the Academy of Management Journal. Academy of Management Journal, 47(4): 454-462.

Ghoshal, S., \& Bartlett, C. A. 1990. The multinational corporation as an interorganizational network. Academy of Management Review, 15(4): 603-625. that deploy qualitative methodology in the forthcoming issues of JIBS.

${ }^{2}$ In addition, two papers were at an advanced stage of revision at the time when the Special Issue was due to be put into production; if accepted, these papers will be published subsequently in a regular issue of JIBS.

${ }^{3}$ This review is particularly valuable as we find that the term "grounded theory" is one of the most misused terms in qualitative studies submitted to management journals. Often this term and the citation of Glaser and Strauss (1967) are used to justify a researcher's going into the field tabula rasa, as it were, without preconceptions or being informed by theory.

Ghoshal, S., \& Bartlett, C. A. 1994. Linking organizational context and managerial action: The dimensions of quality of management. Strategic Management Journal, 15(S2): 91-112.

Glaser, B., \& Strauss, A. 1967. The discovery of grounded theory. Chicago, IL: Aldine Press.

Golden-Biddle, K., \& Locke, K. 2007. Composing qualitative research, (2nd ed.) Thousand Oaks, CA: Sage.

Hamel, G., \& Prahalad, C. K. 1983. Managing strategic responsibility in the MNC. Strategic Management Journal, 4(4): 331-351.

Hedlund, G. 1986. The hypermodern MNC: A heterarchy? Human Resource Management, 25(1): 9-36.

Hofstede, G. 1980. Culture's consequences: International differences in work-related values. Beverly Hills, CA: Sage.

Jick, T. D. 1979. Mixing qualitative and quantitative methods: Triangulation in action. Administrative Science Quarterly, 24(4): 602-611.

Johanson, J., \& Vahlne, J. 1977. The internationalization process of the firm - A model of knowledge development and increasing foreign market commitments. Journal of International Business Studies, 8(1): 23-32.

Kindleberger, C. P. 1956. The terms of trade: European case study. New York: John Wiley \& Sons.

Malnight, T. 1996. The transition from decentralized to network-based MNC structures: An evolutionary perspective. Journal of International Business Studies, 27(1): 43-66.

Marschan-Piekkari, R., \& Welch, C. 2004. The handbook of qualitative research methods for international business. London: Edward Elgar.

Merton, R. K. 1968. Social theory and social structure. New York: Free Press.

Pinder, C. C., \& Moore, L. F. 1979. The resurrection of taxonomy to aid the development of middle range theories of organizational behavior. Administrative Science Quarterly, 24(1): 99-118.

Prahalad, C. K. 1975 . The strategic process in a multinational corporation, Unpublished doctoral dissertation, Harvard University, Cambridge, MA.

Prahalad, C. K., \& Doz, Y. 1987. The multinational mission: Balancing local demands and global vision. New York: Free Press.

Pratt, M. 2009. For the lack of a boilerplate: Tips on writing up (and reviewing) qualitative research. Academy of Management Journal, 52(5): 856-862.

Redding, J. 1994. Strategic readiness: The making of the learning organization. San Francisco: Jossey Bass.

Ritzer, G. 1975. Sociology: A multiple paradigm science. The American Sociologist, 10(3): 156-167.

Roberts, K. H. 1970. On looking at an elephant: An evaluation of cross-cultural research related to organizations. Psychological Bulletin, 74(5): 327-350. 
Sullivan, D., Nerur, S. P., \& Balijepally, V. 2011. Source or storer? IB's performance in a knowledge network. Journal of International Business Studies, 42(3): 446-457.

Tung, R. L. 2008. The cross-cultural research imperative: The need to balance cross-national and intra-national diversity. Journal of International Business Studies, 39(1): 41-46.

Tung, R. L., \& Verbeke, A. 2010. Beyond Hofstede and GLOBE: Improving the quality of cross-cultural research. Journal of International Business Studies, 41(8): 1259-1274.

Van Maanen, J. 1979. Reclaiming qualitative methods for organizational research: A preface. Administrative Science Quarterly, 24(4): 520-526.

Wilkins, M. 1970. The emergence of multinational enterprise: American business abroad from the Colonial Era to 1914. Cambridge, MA: Harvard University Press.

Wilkins, M. 1974. The role of private business in the international diffusion of technology. The Journal of Economic History, 34(1): 166-188.

\section{ABOUT THE AUTHORS}

Julian Birkinshaw is Professor of Strategy and Entrepreneurship at the London Business School. He received his PhD in Business Policy from the Ivey School of Business, Canada. His research focuses on the strategy, organization and management of large Multinational Corporations.

Mary Yoko Brannen is Visiting Professor of Strategy and Management at INSEAD, Fontainebleau. She received her MBA and $\mathrm{PhD}$ in Management with a minor in Anthropology from the University of Massachusetts at Amherst, and a B.A. in Comparative Literature from the University of California at Berkeley. Her research focuses on ethnographic approaches to understanding the effects of changing cultural contexts on technology transfer, work organization, and multinational mergers and acquisitions.

Rosalie L Tung is the Ming \& Stella Wong Professor of International Business at Simon Fraser University. She received her PhD from the University of British Columbia. She is a past President of the Academy of Management. Her research interests are in strategic international human resource management and comparative management. 